\title{
INVESTIGATING EFL LEARNERS' READING SKILLS USING THE COOPERATIVE TEACHING METHOD IN A SAUDI ARABIAN CONTEXT Badia Hakim
}

English Language Institute, King Abdulaziz, University, Jeddah, Saudi Arabia. Email: badiahakim82@gmail.com

\author{
Article History: Received on $24^{\text {th }}$ March 2020, Revised on $30^{\text {th }}$ August 2020, Published on $27^{\text {th }}$ October 2020
}

\begin{abstract}
Purpose: This study aims to investigate the reading skills using a comparative account of two groups of EFL learners' reading achievements.

Methodology: Two gatherings of understudies were chosen and dispersed into a control and a test gathering. The benchmark group was 50 blended capacity middle level 104 understudies who were presented to the regular educator drove procedure of instructing perusing. The exploratory gathering was 50 blended capacity middle of the road level 104 understudies who were instructed with the jigsaw understanding philosophy. The students' age go was between $17-21$ and studied Arts, Mathematics, and Biology.
\end{abstract}

Result: The discoveries of the quantitative examination indicated the positive effect of the jigsaw procedure as a successful helpful learning technique. Contrasted with the ordinary instructor drove showing strategy, the jigsaw method improves the advancement of the understudies' perusing abilities all the more proficiently.

Applications: The results can be used in group work for reading strategies, positively sharing ideas, the participation of each learner in a group as an individual, cooperation, and showing good social skills for sharing knowledge.

Novelty/Originality: The T-test was performed on data-independent samples, which showed a significant difference (P $=0.000$ ) between the data collected from the experimental and control groups. These results have not been observed in the results of other articles so far. This is due to the accuracy of the method used in this method.

Keywords: Teacher-led Method, Jigsaw Reading Method, Cooperative Teaching Method, EFL Learners.

\section{INTRODUCTION}

Cooperative learning methodologies can be fairly characterized by the skill that each learner flourishes with time (Barkley, Cross and Major, 2005). There are numerous cooperative learning techniques including discussion in groups, shared teaching, graphic organizers, writing in groups and problem-solving. Each technique includes a number of prospective structures to lead the growth of a cooperative learning practice. In contrast to conventional strategies, cooperative learning techniques guide learners to take risks and show active participation in their own learning process. Another advantage of introducing the cooperative learning activities is enhancing the chances of peer interaction and eventually encouraging the improvement of language learning and the learning of meaning and structure of the language.

The cooperative language learning approach has an important role in classroom interaction and the arrangement of meaning. The fundamental goal of this approach is to empower the learner to, first and foremost, 'communicate' by using the target language. As suggested by Richards, J. C., \& Rodgers, T. S. (2014), in the history of ELT, the most important concern has been the challenge of the learning of a foreign language. This centrality of learning the foreign language as the most important aim has led to constant developmental changes in language teaching approaches in the field of ELT. This has, in turn, resulted in the prioritization of the learning needs of students/learners in the language learning process. The cooperative teaching methods in English language teaching could be considered a step towards achieving this goal. According to David W. Johnson, Roger T. (1994), the cooperative language teaching methodology is based on the constructivist models of learning, according to which the learning process does not take place in a direct and chronological order but in a collaborative manner by the learners in a self-motivated design. Constructivist models of learning establish the base for the cooperative learning methods in language learning. Some researchers believe constructivism facilitates language learning and that, in contrast to the medium view, the mediation view sheds light on the "understanding of meaning by the practical mediation of the language user in language learning". This supports the idea that in classrooms taught according to the constructivist methodology, language teachers should not be liable solely for communicating knowledge to learners. To this end, well-thought curriculums need to be put in place.

Understudies see Weblog as an apparatus for the advancement of their English, regarding their composing capability and perspectives towards composing. They likewise see Weblog as giving a chance and opportunity for self-articulation in English, composing for a nearby and worldwide crowd, making dynamic, intelligent social trades in web journals, and keeping up an intuitive relationship with a constant readership (Fageeh, A. I. 2011).

In order to align the present study with the previous research on the effect of cooperative techniques on the reading skills of Saudi Arabian EFL learners, the following research question was put forth:

1. What will be the impact of the jigsaw reading technique and the traditional method of teaching on the performance of learners? 
Thus, the point of this examination is to research the perusing aptitudes utilizing a near-record of two gatherings of EFL students' understanding of accomplishments.

\section{REVIEW OF LITERATURE}

According to Johnson, D. W., \& Johnson, R. T. (2011), five key elements distinguish cooperative learning from simple group learning for students.

Positive Interdependence. In positive interdependence, learners "sink or swim together," believing that each person's efforts benefit not only himself or herself but all group members collectively.

It involves setting mutual goals, division of responsibilities, dividing/distributing materials among members of a group, giving roles, and making part of each learner's grade dependent on the performance of the rest of the group.

Individual Accountability. The principle of individual accountability in cooperative learning is "students learn together, but they accomplish the task alone." This ensures that no one can "hitch-hike" on others' work.

Face-to-Face Interaction. Significant logical learning and interpersonal dynamics can only, or primarily, occur when students promote each other's learning in a face-to-face setting.

\section{Interpersonal and Small Group Social Skills}

\section{Group Processing.}

Positive interdependence plays an important role in cooperative learning. That is probably why Kagan places it first in the acronym PIES (Positive Interdependence, Individual Accountability, Equal Participation, and Simultaneous Interaction.) By implementing the approach of positive interdependence, teachers/educators can expose learners to two very practical learning methods.

- Big Project: Learners have often been seen motivated for this task as they (have to) work in groups to accomplish tasks too difficult for a single student to accomplish by themselves in a specific time frame.

- Jigsaw: In this method, learners are divided into groups, working as 'specialists' on specific areas of the material to be learned. These specialists work together to develop expertise in their field, then return to their group(s) to combine their new expertise with those of experts in other areas of the material to finish the project.

The jigsaw strategy has been observed to be more effective with reading techniques. A great deal of research has been conducted to investigate the positive impact of jigsaw with reading tasks. Abd El Sami Ali, M. F. (2001). studied the effect of using the jigsaw reading technique by the EFL teachers and overcoming learner anxiety while doing reading comprehension. His study reported reduced anxiety and stress levels while working in specialist groups and using the jigsaw technique with reading comprehension. Epstein, J. L., \& Dauber, S. L. (1991), also reported that the use of jigsaw in reading comprehension presented further learning opportunities, and in a more relaxed manner/environment, and had a significant positive impact on tension reduction and stress relief when making errors. Other effective techniques in cooperative learning include sharing the responsibilities in a group and division of tasks such as note-taking etc. This effectiveness follows from the fact that, in contrast to conventional teaching models, the cooperative learning approach is based on the tenets of the experiential model of learning. The experiential model helps learners to improve their learning practices and eliminate their learning dogmas. There are five components of cooperative learning that distinguish it from the conventional teacher-led method.

\section{Components of Cooperative Teaching with Positive Interdependence}

\section{Techniques}

In cooperative learning, the idea of positive interdependence means learners are placed in groups where one can affect all, either in advantageous or disadvantageous ways. Fundamental to cooperative learning is the idea that learning is more effective when there are more participation and cooperation than competition, between learners. If there is no cooperation and/in positive interdependence, no learning, but simply an endless group work process with no direction, will take place.

\section{Formation of Groups}

The most important factor in having constructive and positive interdependence is having equally constructive and informed formation of groups. When forming the groups, certain factors play an important role in the success of the group such as group size, division of tasks in the group, and level of participation by learners. As stated by to Olsen and Kagan (Richards, J. C., \& Rodgers, T. S. 2014), in groups with concrete and well-planned implementation of positive interdependence, an improved learning process is witnessed to take place.

\section{Discrete rate of performance by learners}

The concept of individual learners' rate of performance in positive interdependence has a significant impact on work productivity, which is based on the hypothesis that though performing in a group has a combined productivity effect, 
still, each learner is responsible for their role played as an individual. The idea that group productivity could be affected by individual performance/input was put forward following it up by listing three essential characteristics of individual liability, i.e. a. purely individual performance without any support system, b. Individual performance is seen and checked by a second party, c. mandatory requirement of constructive performance. The triangular component structure clearly indicates that the success of any lesson of the group project or assigned activities is purely dependent on the learners' individual liability towards their assigned role.

\section{Collegial Role}

'Collegial role' refers to multiple ways in which learners interact with each other in an assigned group activity. It is a problem-solving strategy that finds and provides solutions to learners to help them with issues they find personally difficult. These techniques particularly help learners who are reluctant to participate due to psychological factors such as shyness, stubbornness, and aggressive attitude. The collegial role helps such learners enhance their group participation, increase their level of group performance, and successfully complete the assigned task.

\section{Organization of performance structures}

'Organization of performance structures' refers to strategies used to handle the collegially constructed activities with maximum performance rate. They help design various 'activities' patterns according to the given framework of cooperative learning. According to Olsen and Kagan (Richards, J. C., \& Rodgers, T. S. 2014), there are some successfully experimented techniques, such as "a. Roundtable, b. Three-tier interview, c. Think-pair-share, d. Solve-pairshare, e. Numbered heads, etc." Instead of merely focusing on the end result, as in most conventional collegial activity, these approaches motivate the learners' intellectual strength, reasoning, and logical participation in the learning process. Conventional teaching methods in the language learning process, on the contrary, only aim for the end result of the teaching process or period. To this end, Pica, T. (2000), suggests techniques such as the use of grammar exercises, doing dictation, and memorization as conventional teaching techniques that can yield the most immediate and efficient results. She acknowledges that such activities are based on conventional techniques of linear teaching and giving curative feedback. In other words, the conventional teaching method of language teaching advocates transcribing the core body of any knowledge item from the teacher to the learners without taking into account the teacher's innovative capabilities and/or learners' effective participation in the learning process.

\section{Approaches and techniques used in cooperative Learning}

There are various techniques used in cooperative learning that are designed to encourage students' participation in an environment of interactive learning. These techniques also help promote learners' social skills and increase participation. Shaaban, K., \& Ghaith, G. (2005) offers a list of these techniques including Jigsaw (Aronson, E., et.al. 1978), Constructive Controversy (CC) (Johnson, D. W., \& Johnson, R. T. 2011), Group Investigation (GI) (Sharan, S., \& Sharan, Y. 1976), Complex Instruction (CI) (Cohen, D., et. al. 1986), and Cooperative Structures (CS) (Kagan, S. 1985).

\section{Jigsaw technique}

Jigsaw is an interesting technique and a cooperative learning method that ensures maximum learner interaction. It helps learners accomplish their specific aims in/via the planned activity. The steps followed in this technique are:

A. Learners read the assigned material;

B. Group discussion follows;

C. Learners report to their base team;

D. Collecting team credit.

Jigsaw is a cooperative learning method in which learners read the given content form syllabus and then take a teaching role for a smaller group of peers (Aronson, E., et. al. 1978). Jigsaw learning strategy allows learners to master one assigned segment of the main content. Learners meet with members from other groups who are mastering the same segment, and after grasping the idea of the given content, they return to the base group and teach that item to their group members. By using this method, every learner in the base group plays a role as a piece of a puzzle and when they all join back and match the pieces together as a whole, they help complete the entire (jigsaw) puzzle (p.104)

\section{Reading as a receptive skill in cooperative learning}

Like other receptive (aka input) skills of language learning, reading can also be taught more efficiently by applying the methods and techniques of the cooperative learning approach. Many studies have been done in this area and their findings confirm the high success rate of this method for teaching reading. Some important findings are detailed below.

There is a great deal of difference between the effects of the cooperative integrated reading and composition (CIRC) technique and the conventional reading and writing teaching techniques on the reading-writing skills of learners (Durukan, E. 2011). According to Durukan, the CIRC method uses the cooperative teaching approach and the formation of small groups to integrate the reading and writing skills. Whereas, the conventional method of teaching uses the old 
traditional approach that is mainly based on the distinctive individualistic method of teaching reading and writing skills. A similar study by $\mathrm{Wu}, \mathrm{T}$. T., et.al (2018). investigates the effects of the cooperative learning approach and the conventional teacher-led lecture method of teaching separately on learners' reading comprehension skill development and reports similar results.

\section{Effects of Cooperative Learning on Reading Skill in a Saudi Arabian context}

A detailed study was carried out by Khorshidi (1999) to study the possible link between the use of the cooperative learning approach and/or the traditional teacher-led approach for language learners' better understanding of reading comprehension. In his study, he also observed the effect of mixed-ability heterogeneous groups and similar-level homogenous groups of learners on their performance and on their ability to comprehend reading tasks. For the heterogeneous group, there were four different aspects of the reading study and for the homogeneous group, there was only one. There was a clear difference indicated by results in the outcome of the experimental groups and the control group. Learners in the heterogeneous group outperformed the homogeneous/control group by a large margin. In a similar study, Jalilifar, A. (2010). examined the efficiency of the two techniques used in cooperative learning, one group named the 'student team achievement divisions' (STAD) and the other 'group investigation' (GI) with regard to the reading achievement of students. The cooperative learning method for reading was administered to the experimental group and the traditional teacher-led method of teaching reading to the control group. The findings of the research were analyzed and they clearly reflected a great difference between the two groups. The experimental group, subjected to the cooperative learning method, showed better performance compared to the control group, subjected to the traditional method. In his research, Rahvard, Z. J. (2010) studies the effects of the cooperative learning method on reading comprehension of intermediate-level EFL students. The experimental group was given stories to read in four multiple groups but the control group was not exposed to any such technique. As expected, the results showed better performance/achievement by the experimental group. In the conclusion of her study, the researcher acknowledged that having positive interdependence was the most important factor while working in a group with cooperative learning techniques.

\section{Improvement in Reading skill by using Jigsaw}

In his study, Abd El Sami Ali, M. F. (2001), studied the effect of using the jigsaw reading technique on novice EFL teachers to gauge their reading anxiety and comprehension capability for the given content. The experimental group was subjected to the cooperative learning method of Jigsaw reading for multiple reading content whereas the control group was asked to read the passages individually. Their level of competence was evaluated by the TOEFL test and their level of nervousness was assessed using a questionnaire. As expected, the results showed lower anxiety level and better performance and learning capability from the experimental group as compared to the control group, with higher anxiety level and lower learning. Badawi (2008) also studied learners' achievement level in reading when subjected to the jigsaw reading method, as compared to the traditional individual reading method. The findings of his study reported no significant differences between the control and experimental groups in terms of acquiring new lexical items and reading time but meaningful differences in concept gain, the value of the given task, and in the motivation level of the learners in both groups.

\section{METHODOLOGY}

\section{Target learners}

Two groups of students were selected and distributed into a control and an experimental group. The control group was 50 mixed-ability intermediate level 104 students with $(\mathrm{N}=23=$ Male $)$ and $(\mathrm{N}=27=$ Female $)$ who were exposed to the conventional teacher-led methodology of teaching reading. The experimental group was 50 mixed-ability intermediate level 104 students with $(\mathrm{N}=22=$ Male $)$ and $(\mathrm{N}=28=$ Female $)$ who were taught with the jigsaw reading methodology. The learners' age range was between $17-21$ and they majored in Arts, Mathematics, and Biology. They were initially placed in the Intermediate level after taking a standard OUP placement test. Participants were all native Arabic speakers and learners of English as a foreign language who had studied English in three levels from beginners to elementary in levels 101, 102, and 103. Learners in both control and experimental groups were made sure to take the pre-test and the post-test in the reading skill. The experimental group was subjected to the jigsaw reading technique and the control group to the traditional teacher-led reading method.

\section{Experimental tools}

As the experimental tool, OUP (Oxford University Press) placement test was administered, in components and as a whole, in order to gauge the proficiency level of the participants. Only the reading comprehension part was selected from the OUPLT and the grammar and vocabulary section was omitted. Learners were asked to provide answers to the questions related to the given text. Various types of questions were used in the test such as open-ended, long-answer, short-answer, main idea-based, and inferential questions. The textbook used in the experiment was the Interaction book (OUP), selected due to the assumed suitability of the reading material for intermediate-level students. The book has general-content reading passages, stimulating for learners of varying interests and special groups, employs very effective reading techniques, and makes outstanding use of lexical items, grammar, and writing exercises. Overall, the standard of 
the book and the selected reading passages aligned with the objectives of the cooperative language learning and the jigsaw method used in the study.

\section{Procedural techniques}

For the learners of both (control and experimental) groups, the classes were organized in a special way: All learners were supposed to attend the English Language classes 3 days per week, each session lasting for 2 hours and 30 minutes. All participants were subjected to an OUP placement test to ensure a certain standard for the learners in each group. After administering the OUPLT and distributing the learners into their respective groups, the selected cooperative learning techniques, including the jigsaw reading, were experimented on the participants of the experimental group in a span of a 7-week module, with 15 classes in total. The arrangement of lessons (lesson planning) was left to teachers but it was made sure that the teacher introduced the reading passage and assigned pre-reading and background knowledge by using a set of planned activities. The instrumentation of the jigsaw reading method to the experimental group was in line with the guidelines identified by Coelho (Richards, J. C., \& Rodgers, T. S. 2014):

1. Each reading passage was divided into four parts, depending on the length of the passage, and then each member received one part to read and comprehend. Then, each member of the base group would read the part of the reading passage assigned to him/her in order to familiarize the entire group with the main idea and the sequence of the given reading material.

2. In the next step, learners from the base group were regrouped into the subtopic groups (specialist groups) consisting of learners with the same reading piece, to rehearse their skills and to master the content, and prepare to teach.

3. Learners were then asked to get back to the base group and share the information they mastered in teaching.

4. Learners imparted the knowledge to others in the base group through discussion and negotiation.

5. In the final stage, each learner was asked to prepare an assignment as a part of a group project or was given a quiz, to validate the blending and understanding of the information presented by the participants. By using this method, teachers can evaluate the understanding of full reading passages through students' presentations and/or quiz performance. The sequence of this procedure was carefully planned, timed out, and observed by the teacher, for the experimental group in particular. These evaluative sessions lasted for 60 minutes for each session. Learners in the control group, on the other hand, were subjected to a teacher-led, purely conventional method of teaching reading. The conventional method, adopted for the control group, was very simple and straightforward where the teacher started the passage by reading it aloud for the learners and then translating the entire passage, sentence by sentence, into the students' native language, i.e. Arabic. After explaining the entire passage and 'imparting' the needed information to the students, the teacher asked students to do the exercises independently. The teacher then explained the new lexical items in the passage by translating them directly into Arabic, followed by deductively explaining the main grammar items from each passage in Arabic. There was hardly any interactive pattern and/or stimulant used by the teacher as it was mainly a teacher-centered, teacher-initiated class. The same teacher was responsible for the task of separating learners from the experimental and control groups. In order to evaluate learners' performance after 15 sessions of exposure to their respective teaching methods, a post-test for the reading skill was administered. The post-test was designed as a multiple-choice test with almost $50 \mathrm{MCQs}$ to examine learners' performance and comprehension.

\section{RESULTS}

After collecting the data from both groups, a sample t-test was run on the collected data. This test was integral especially to the research question and to examining the efficacy of both methods for experimental and control groups. The statistics of the data from both groups are given below in Table 1.

Table 1: Statistics of the data from the experimental and the control group

\begin{tabular}{cccccc}
\hline Groups & Number (N) & Mean value & $\begin{array}{c}\text { Standard } \\
\text { deviation }\end{array}$ & $\begin{array}{c}\text { Standard error } \\
\text { - Mean }\end{array}$ \\
\hline Posttest & Control & 49 & 25.8456 & 3.5876 & 0.5765 \\
\hline & Experimental & 50 & 29.5680 & 5.2709 & 0.76532 \\
\hline
\end{tabular}

As the above table and the descriptive statistical analysis show, learners in the experimental group who received the jigsaw cooperative instruction outperformed learners in the control group in terms of the mean scores.

Table 2 shows the samples t-test results analysis.

Table 2: Statistics of the data from sample t-test analysis from the experimental and the control group

\begin{tabular}{ccccccccc}
\hline $\begin{array}{c}\text { Levene's Test for Equality of } \\
\text { Variances }\end{array}$ & \multicolumn{1}{c}{ T-test for Equality } \\
of Means
\end{tabular}




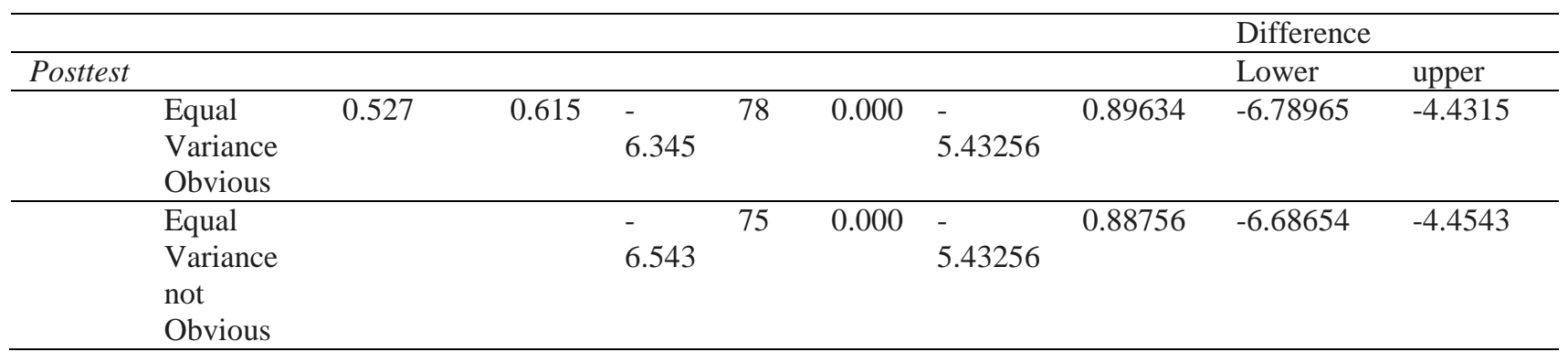

\section{DISCUSSION}

The analysis of results reflected a significant level of Levene's test, at $\mathrm{p}=0.527$, showing that the variances (obvious and not obvious) for the two groups of learners (experimental and control) were almost the same. The analysis of the t-test also demonstrated a substantial difference in the performance of learners in the experimental group and the control group while doing reading comprehension $(\mathrm{t}(78)=-5.4325, \mathrm{p}=0.000)$. This result was confirmed by the results obtained from the descriptive analysis. The mean values for the descriptive analysis reflected a substantial variance between the participants of the experimental group and the control group in terms of the mean scores, with learners in the experimental group outperforming learners in the control group by a large margin.

The findings of the quantitative analysis showed the positive impact of the jigsaw technique as an effective cooperative learning method. Compared to the conventional teacher-led teaching method, the jigsaw technique improves the development of the students' reading skills more efficiently. The results of this study coincide with the findings of other research done so far, all confirming the fact that the cooperative learning methods, including jigsaw and especially with regards to learners' reading skills, have a significantly better impact, as compared to the traditional teacher-led less interactive methods.

\section{CONCLUSION}

The current research focused on investigating the potential efficacy of the jigsaw method of reading as compared with the conventional teacher-led, grammar-based method. It confirms the findings of previous studies regarding the contention that the jigsaw reading method enhances learners' ability to learn through active interaction and by implementing the principles of the cooperative teaching approach. The cooperative approach is conducive to the generation of positive interdependence, amiability, and interactiveness and contributes to effective learning. It is a truth universally acknowledged that an interactive learning environment tends to bring success to the learners, which is in line with the Vygotskian conviction that even low-performing learners can improve and enhance their performance by getting exposed to interactive learning techniques. It is an on-going journey from improved performance to objectregulation and finally to self-regulation where a learner starts performing well independently. In the conventional teacher-led method, on the other hand, the teacher has a/the pivotal role where, consequently, learners are not motivated to interact and learn from each other. In such a teacher-centered methodology, learners have the least participation in the class as they just stay there as passive listeners. Cooperative and conventional methods have very different approaches to improving the performance in the process of effective language learning, though the former proves more efficient in successive studies.

\section{LIMITATION AND STUDY FORWARD}

Increasing the number of people studied can increase the accuracy of the study.

\section{ACKNOWLEDGMENTS}

The author confirms that the data do not contain any conflict of interest.

\section{REFERENCES}

1. Abd El Sami Ali, M. F. (2001). The effect of using jigsaw reading technique on the EFL pre-service teachers' reading anxiety and comprehension. Journal of Education College, 3, 1-21.

2. Aronson, E., Blaney, N., Stephan, C., Sikes, J., \& Snapp, M. (1978). The jigsaw classroom. Beverly Hills.

3. Ashman, A., \& Gillies, R. (Eds.). (2003). Cooperative learning: The social and intellectual outcomes of learning in groups. Routledge. https://doi.org/10.4324/9780203465264

4. Badawi, G. H. (2008). The effect of jigsaw on the entire class instruction on EFL students' reading motivation and achievement. Cooperative learning techniques https://serc.carleton.edu/introgeo/co operative/techniques.html.

5. Cohen, D., Gopinath, B., Honig, M., Keese, W., Levin, P., Myers, J., ... \& Vollaro, J. (1986). C: an environment for specifying complex systems. In Unknown Host Publication Title (pp. 632-637). IEEE.

6. Epstein, J. L., \& Dauber, S. L. (1991). School programs and teacher practices of parent involvement in innercity elementary and middle schools. The elementary school journal,91(3), 289-305. https://doi.org/10.1086/461656 
7. Wu, T. T., Huang, Y. M., Shadiev, R., Lin, L., \& Starčič, A. I. (Eds.). (2018). Innovative Technologies and Learning: First International Conference, ICITL 2018, Portoroz, Slovenia, August 27-30, 2018, Proceedings (Vol. 11003). Springer. https://doi.org/10.1007/978-3-319-99737-7

8. David W. Johnson, Roger T. (1994). Johnson, Edythe Johnson Holubec -Association for Supervision and Curriculum Development, Education.

9. Durukan, E. (2011). Effects of cooperative integrated reading and composition (CIRC) technique on readingwriting skills. Educational Research and Reviews, 6(1), 102.

10. Jalilifar, A. (2010). The effect of cooperative learning techniques on college students' reading comprehension. System, 38(1), 96-108. https://doi.org/10.1016/j.system.2009.12.009

11. Johnson, D. W., \& Johnson, R. T. (2011). Cooperative learning. The encyclopedia of peace psychology. https://doi.org/10.1002/9780470672532.wbepp066

12. Kagan, S. (1985). Dimensions of cooperative classroom structures. In Learning to cooperate, cooperating to learn (pp. 67-96). Springer, Boston, MA. https://doi.org/10.1007/978-1-4899-3650-9 3

13. Khorshidi, M. (1999). Cooperative learning and reading comprehension. Unpublished Master of Arts thesis, University of Science and Technology, Iran. Retrieved July, 9, 2011.

14. Pica, T. (2000). Tradition and transition in English language teaching methodology. System, 28(1), 1-18. https://doi.org/10.1016/S0346-251X(99)00057-3

15. Rahvard, Z. J. (2010). Cooperative learning strategies and reading comprehension. California Linguistic Notes, 35(2), 1-15.

16. Richards, J. C., \& Rodgers, T. S. (2014). Approaches and methods in language teaching. Cambridge university press.

17. Shaaban, K., \& Ghaith, G. (2005). The theoretical relevance and efficacy of using cooperative learning in the ESL/EFL classroom. TESL Reporter, 38(2), 14-28.

18. Sharan, S., \& Sharan, Y. (1976). Small-group teaching.

19. Fageeh, A. I. (2011). EFL learners' use of blogging for developing writing skills and enhancing attitudes towards English learning: An exploratory study. Journal of Language and Literature, 2(1), 31-48.

20. Mahmoud, M. M. A. (2014). The effectiveness of using the cooperative language learning approach to enhance EFL writing skills among Saudi university students. Journal of Language Teaching and Research, 5(3), 616. https://doi.org/10.4304/jltr.5.3.616-625 